\title{
A state-of-the-art survey of malware detection approaches using data mining techniques
}

\author{
Alireza Souri $^{1 *}$ (ID and Rahil Hosseini ${ }^{2}$
}

*Correspondence:
a.souri@srbiau.ac.ir
${ }^{1}$ Department of Computer
Engineering, Science
and Research Branch, Islamic
Azad University, Tehran, Iran
Full list of author information
is available at the end of the
article

*Correspondence:

a.souri@srbiau.ac.

Engineering, Science

and Research Branch, Islamic

Avad University, Tehran, Iran

article

\begin{abstract}
Data mining techniques have been concentrated for malware detection in the recent decade. The battle between security analyzers and malware scholars is everlasting as innovation grows. The proposed methodologies are not adequate while evolutionary and complex nature of malware is changing quickly and therefore turn out to be harder to recognize. This paper presents a systematic and detailed survey of the malware detection mechanisms using data mining techniques. In addition, it classifies the malware detection approaches in two main categories including signature-based methods and behavior-based detection. The main contributions of this paper are: (1) providing a summary of the current challenges related to the malware detection approaches in data mining, (2) presenting a systematic and categorized overview of the current approaches to machine learning mechanisms, (3) exploring the structure of the significant methods in the malware detection approach and (4) discussing the important factors of classification malware approaches in the data mining. The detection approaches have been compared with each other according to their importance factors. The advantages and disadvantages of them were discussed in terms of data mining models, their evaluation method and their proficiency. This survey helps researchers to have a general comprehension of the malware detection field and for specialists to do consequent examinations.
\end{abstract}

Keywords: Data mining, Malware detection, Classification, Behavior-based, Signaturebased

\section{Introduction}

In the recent years, the application of malware detection mechanisms utilize through data mining techniques through have increased using machine learning to recognize malicious files $[1,2]$. Machine learning methods can take in hidden examples from a given preparing set which includes both malware and benign examples. These basic examples can separate malware from benevolent code [3, 4]. Malware is a standout most thoughtful intimidations for distributed systems and the Internet [5]. The battle between security analyzers and malware scholars is everlasting as innovation grows. Malware is a program that makes your framework accomplish something that an assailant needs it to do [6]. The most generally utilized malware detection develops a straightforward example coordinating way to deal with identify vindictive code. Typically malware designers

(c) The Author(s) 2018. This article is distributed under the terms of the Creative Commons Attribution 4.0 International License (http://creativecommons.org/licenses/by/4.0/), which permits unrestricted use, distribution, and reproduction in any medium, provided you give appropriate credit to the original author(s) and the source, provide a link to the Creative Commons license, and indicate if changes were made. 
don't compose new code without any preparation, yet redesign the old code with new components or muddling strategies [7]. With a large number of malware cases seeming each day, proficiently preparing countless specimens which display comparable conduct, has turned out to be progressively essential [8].

Up to now, malware analysis $[9,10]$ have the high growing impact in the procedure of deciding the reason and the usefulness the conduct of a given suspicious application. Such a procedure is an important essential with a specific end goal to create effective and powerful identification furthermore characterization techniques; malware analysis is partitioned into two primary classifications that include dynamic and static methods $[11,12]$. To the best of our knowledge, the most data mining methods have some benefits and weaknesses in malware detection subject [13]. In addition, having a new literature review can be influenced on the research studies and explore some technical details in malware detection using data mining techniques. Of course, some research [13-17] had discussed the malware detection approaches. There are some defects in the surveyed research. Some papers are published in out of date and did not considered new articles in comparison and analysis. In addition, some surveys have not any systematic classification and article selection for their researches. For example, Muazzam Siddiqui et al. [18] presented a survey of malware detection using data mining techniques. Some defects of the survey are as follow: this survey used old research in literature analysis. In addition, they did not any systematic review for article selection in their research. This research did not specified an appropriate categorization for malware detection techniques. Just, they analyzed the scanning and data analysis methods in the proposed research.

To overcome some defects, this paper presents a systematic literature review on the new recent malware detection techniques using data mining approaches. This review classifies the malware detection approaches in two main fields: signature-based and behavior-based. The contributions of this paper are as follows:

- Providing a summary of the current challenges related to malware detection approaches in data mining.

- Presenting a systematic and categorized overview of the current approaches to machine learning mechanisms in the data mining topics.

- Exploring a structure of the important methods that are significant in malware detection approach.

- Discussing the important factors of classification malware approaches in the data mining to improve their problems in the futures.

The rest of this paper organized as follows. "Malware detection approaches", overviews the malware detection mechanisms in data mining methods and classifies them with a technical taxonomy. "Review of the malware detection approaches" presents an analytical comparison of the proposed approaches for selected studies. In "Discussion", a discussion about the malware detection issues is shown that have not been analyzed comprehensively up to now as an exploration of new challenges. Finally, "Conclusion" displays the conclusion. 


\section{Malware detection approaches}

As a result of the developing malware in the innovation, the information of obscure malware protection is a fundamental subject in the malware recognition as per the machine learning strategies [19]. The machine learning strategies are divided into supervised and unsupervised classes. Malware detection approaches are divided into two main categories that include behavior-based and signature-based methods [20]. Also, there are two static and dynamic [21] malware analysis that generally performed in finding malicious applications [22].

In Fig. 1, we illustrate a malware detection taxonomy based on machine learning approaches. According to this figure, the API calls features, assembly features, and binary features are existing approaches for malware detection method. These features use machine learning methods for predicting and detecting malicious files.

\section{Signature-based malware detection}

Recently, signature-based detection is the most generally utilized procedure in antivirus programming highlighting exact correlation. Malware recognition has essentially centered on performing static investigations to review the code-structure mark of infections, instead of element behavioral methods [23]. The signature-based system finds interruptions utilizing a predefined list of known assaults. Despite the fact that this arrangement has the ability to identify malware in the versatile application, it requires steady overhauling of the predefined signature database. Moreover, it is less effective in identifying noxious exercises utilizing the signature-based technique because of the quickly changing nature of portable malware [24, 25]. Signature-based strategies depend in light of exceptional crude byte examples or standard articulations, known as marks, made to coordinate the noxious document. For example, static highlights of a record are utilized to decide if it is a malware. The main advantage of signature-based techniques is their thoroughness since they follow all conceivable execution ways of a given document.

In inside of the malware structure, existing malicious objects have characteristics that can be used to generate a unique digital signature. The anti-malware provider utilizes the meta-heuristic algorithms that can scan efficiently the malicious object to control its signature [26]. After identifying the malicious object, the detected signature is added

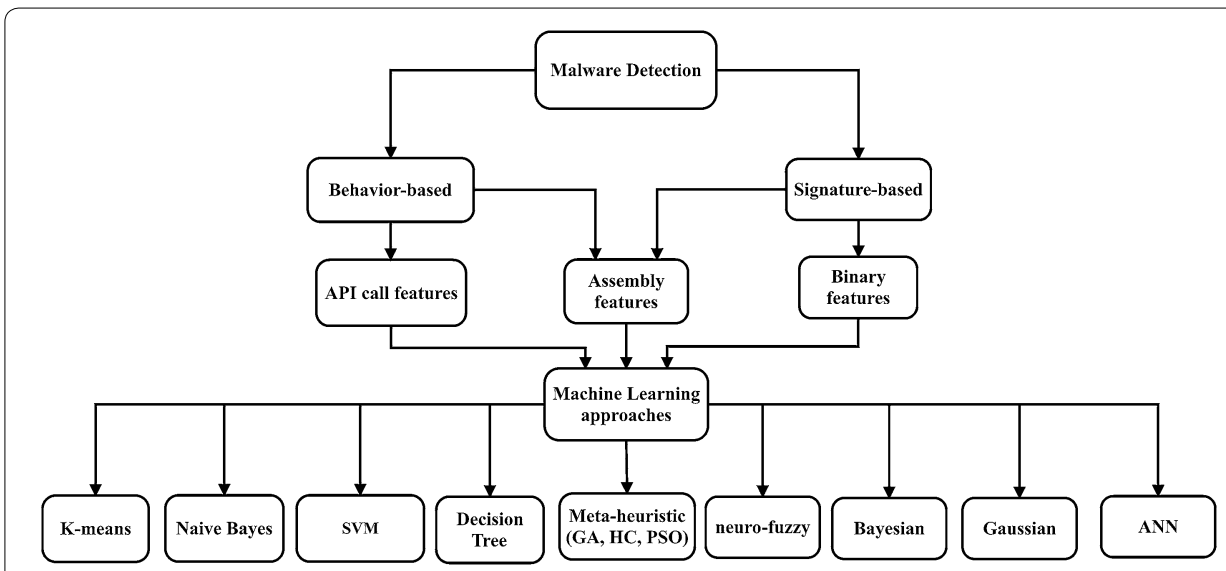

Fig. 1 Taxonomy of malware detection approaches 
to the existing database as the recognized malware. The database sources include huge number of the various signatures that classify malicious objects. In the signature-based malware detection, there are some various qualities including fast identification, easy to run, and broadly accessible [27].

Since the digital signature plans are gotten from known malware, these plans are likewise generally known. Subsequently they can be effectively evaded by programmers utilizing straightforward confusion procedures. Hence malware code can be modified and signature-based identification can be sidestepped. Since anti-malware providers are built on the premise of known malware, they can't to distinguish obscure malware, or even variations of known malware. In this way, without exact digital signature, they can't adequately distinguish polymorphic malware. Along these lines, signature-based recognition does not give zero-day insurance. Besides, since a signature-based indicator utilizes an isolate signature for each malware variation, the database of signatures develops at an exponential rate [28]. The signature-based malware detection has two main methods for applying malware detection approach in machine learning methods including assembly features and binary features. Figure 2 illustrates a standard signature-based malware detection framework using data mining approaches.

Also, Table 1 shows the advantages and weaknesses of the signature-based malware detection approach.

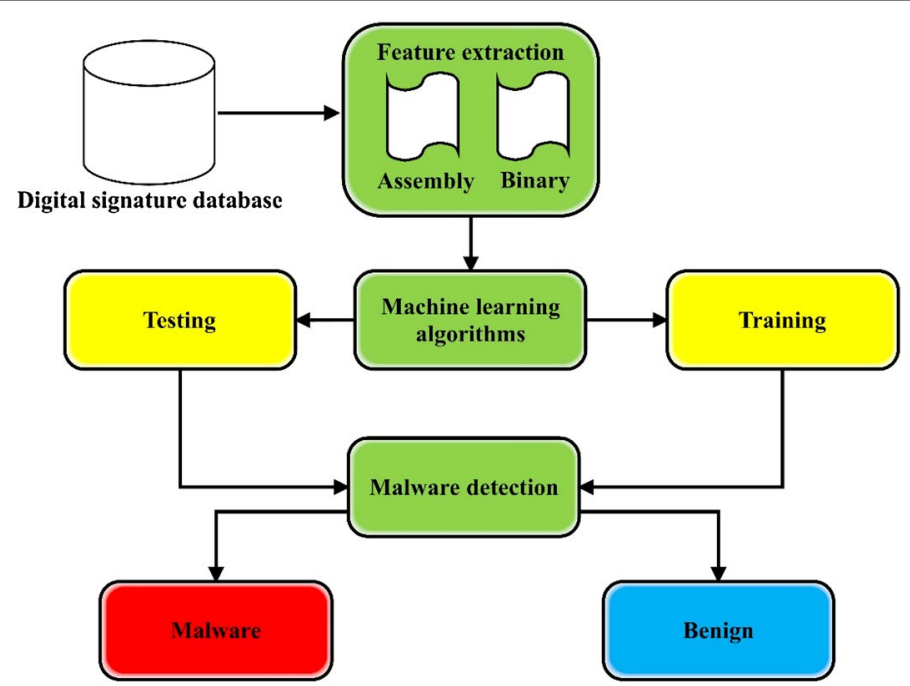

Fig. 2 The signature-based malware detection framework

Table 1 The advantages and weaknesses of the signature-based detection

\begin{tabular}{ll}
\hline Advantage & Weakness \\
\hline Easy to run & Failing to detect the polymorphic malwares \\
Fast identification & Replicating information in the huge database \\
Broadly accessible & \\
Finding comprehensive malware information & \\
\hline
\end{tabular}




\section{Behavior-based malware detection}

This subsection illustrates the behavior-based approaches in malware detection. In addition, it reviews the selected behavior-based approaches in the data mining. Finally, the discussed behavior-based approaches compared and summarized in the last subsection. Behavior-based methodologies require execution of a given example in a sandboxed situation and run-time exercises are checked and logged. Dynamic investigation systems utilize both virtualization and imitating conditions to execute a malware and to remove its practices. The primary advantage of the behavior-based approach is that gives a superior comprehension of how malware is produced and implemented $[8,14]$.

In the behavior-based malware approach, the suspicious objects are assessed based on their activities that they cannot execute in system. Efforts to achieve activities that are clearly irregular or unofficial would specify the suspicious object is malicious, or at least apprehensive. A malicious behavior is known using a dynamic analysis that evaluates malicious intent by the object's code and structure. In the behavior-based detection, the API calls and assembly features are two main methods for applying machine learning algorithms. Figure 3 depicts a standard behavior-based malware detection approach using data mining algorithms.

Table 2 shows the advantages and weaknesses of the behavior-based malware detection approach.

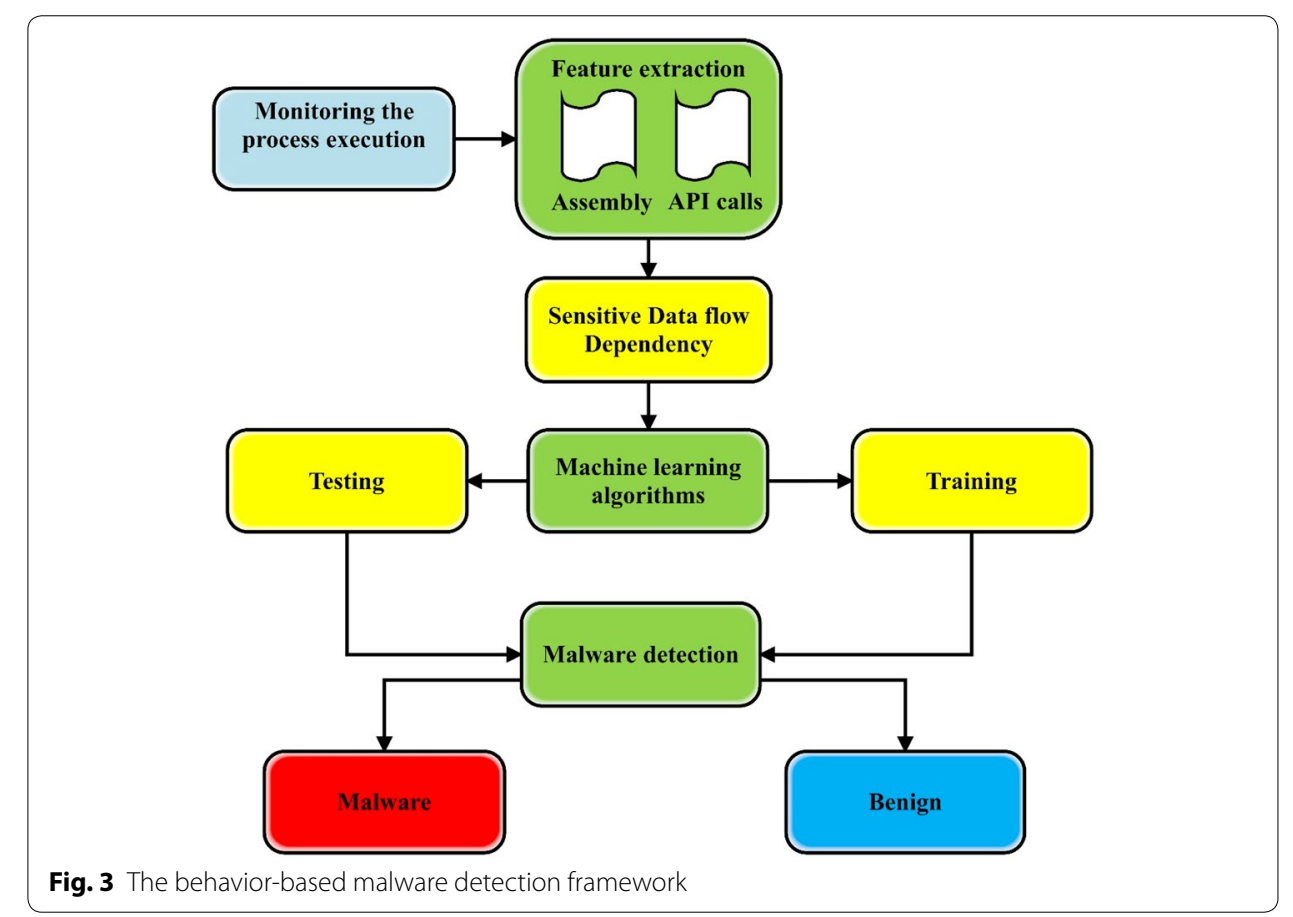

Table 2 The advantages and weaknesses of the behavior-based detection

\begin{tabular}{ll}
\hline Advantage & Weakness \\
\hline Detecting unconceived types of malware attacks & Storage complexity for behavioral patterns \\
Data-flow dependency detector & Time complexity \\
Detecting the polymorphic malwares & \\
\hline
\end{tabular}


After describing the existing malware detection approaches, next section presents the technical analysis of the current research studies in the malware detection with data mining algorithms.

\section{Review of the malware detection approaches}

In this section, the existing malware detection approaches are analyzed according to some evaluation factors such as the main idea, advantages and disadvantages, algorithm type and assessment type in data mining techniques. We analyze the selected studies according to existing approaches and discuss on them.

\section{Review of the signature-based approaches}

Wu et al. [29] have utilized an artificial immune-based smartphone malware detection model (SP-MDM) both static malware examination and element malware investigation as indicated by the component of the biologic resistant framework that can shield us from disease by creatures. In this model, the static marks and dynamic marks of malware are separated, and in view of the genuine esteemed vector encoding, the antigens are produced. The youthful identifier develops into a develop one on the off chance that it experiences self-resistance. Finder posterity with higher fondness is made after the streamlining of developing identifiers utilizing clonal determination calculation. Also, they collected twenty malware and twenty benign files as testing samples set.

Bat-Erdene et al. [30] presented a strategy for characterizing the packing algorithms of given unknown packed executable. To begin with, they measured the entropy estimations of a given executable and change over the entropy estimations of a specific area of memory into typical representations. Their presented strategy utilized symbolic aggregate approximation (SAX), which is known to be viable for huge information changes. Second, we order the conveyance of images utilizing managed learning order strategies, i.e., credulous Bayes and bolster vector machines for recognizing pressing calculations. The aftereffects of our examinations including a gathering of 324 pressed kindhearted projects and 326 stuffed malware programs with 19 pressing calculations illustrate that our strategy can distinguish pressing calculations of given executable with a high precision of $95.35 \%$, a review of $95.83 \%$, and an accuracy of $94.13 \%$. We propose four likeness estimations for distinguishing pressing calculations based on SAX representations of the entropy values and an incremental total examination. Among these four measurements, the loyalty closeness estimation shows the best-matching result, i.e., a rate of precision running from 95.0 to $99.9 \%$, which is from 2 to 13 higher than that of the other three measurements. Our review affirms that pressing calculations can be recognized through an entropy examination in view of a measure of the instability of the running procedures and without earlier information of the executable.

Cui et al. [31] illustrated a novel recognition framework in light of cloud environment and packet examination. The framework identifies the malicious mobile malware behavior through their bundles with the utilization of information mining strategies. This approach totally keeps away from the deformities of customary techniques. The framework is administration arranged and can be sent by portable administrators to send cautions to clients who have malware on their gadgets. To enhance framework execution, another bunching technique called withdrawal grouping was made. This technique 
utilizes earlier learning to lessen dataset measure. In addition, a multi-module location plan was acquainted with improve framework precision. The aftereffects of this plan are created by incorporating the location consequences of a few calculations, including Naive Bayes and Decision Tree.

Fan et al. [32] proposed a compelling arrangement mining calculation to find vindictive quintal examples, and afterward, All-Nearest-Neighbor (ANN) classifier is constructed for malicious position in the established samples. The created information mining structure made out of the proposed consecutive example mining technique and ANN classifier can well describe the malevolent examples from the gathered record test set to adequately distinguish recently concealed malware tests. A thorough exploratory review on a genuine information accumulation is performed to assess our recognition structure. The promising test comes about demonstrate that their structure beats other to exchange information mining based discovery techniques in distinguishing new vindictive executable.

Hellal and Ben Romdhane [33] displayed another diagram mining technique to recognize variations of malware utilizing static examination while covering the current defects. Also, they proposed a novel calculation, called minimal contrast frequent subgraph miner method (MCFSM), for separating negligible discriminative and generally utilized malevolent behavioral designs which can distinguish definitely a whole group of vindictive projects, conversely to another arrangement of benevolent projects. The proposed technique demonstrates high recognition rates and low false positive rates and creates a predetermined number of behavioral malware marks.

Martín et al. [34] illustrated outsider calls to sidestep the impacts of these disguise methodologies since they can't be obfuscated. We join bunching and multi-target advancement to produce a classifier in view of particular practices characterized by outsider call bunches. The analyzer guarantees that these gatherings are identified with noxious or favorable practices cleaning any non-discriminative example. This device, named MOCDroid, ${ }^{1}$ accomplishes a precision of $95.15 \%$ in test with $1.69 \%$ of false positives with genuine applications extricated from the wild, overcoming all business antivirus motors from VirusTotal.

Santos et al. [35] proposed another strategy to identify obscure malware families. This model depends on the recurrence of the presence of opcode groupings. Moreover, they depicted a system to mine the importance of each opcode and evaluate the recurrence of each opcode grouping. Furthermore, they provided experimental approval that this new strategy is fit for recognizing obscure malware.

Wang and Wang [24] presented a malware recognition framework to ensure a little order mistake by machine learning using the speculation capacity of support vector models (SVMs). This review built up a programmed malware location framework via preparing a SVM classifier in light of behavioral marks. Over approval, plan was utilized for taking care of grouping exactness issues by utilizing SVMs connected with 60 groups of genuine malware. The trial comes about uncover that the characterization blunder diminishes as the measuring of testing information is expanded. For various estimating $(\mathrm{N})$ of malware tests, the expectation precision of malware discovery runs up to $98.7 \%$

${ }^{1}$ Multi-objective classifier detection. 
with $\mathrm{N}=100$. The general recognition precision of the $\mathrm{SVC}$ is more than $85 \%$ for unspecific versatile malware.

\section{Summary of the reviewed signature-based approaches}

According to the discussed and reviewed signature-based detection approaches, the comparison of the proposed articles is demonstrated in Table 3 which shows the used case study in research, the main advantages, disadvantages and target environment for the existing studies. The main advantage of signature-based detection approaches is using pattern detection that decreases the system overhead and execution time for malware prediction. The main disadvantage of the signature-based detection approaches is omitting feature selection. The target environment is categorized into three main platforms including embedded systems, Windows-based and smartphones. The most research studies in the signature-based detection have used the Windows-based environment for representing the proposed malware detection approach.

In addition, Table 4 depicts a side-by-side comparison of the signature-based detection factors in each article. These factors include case-study method, classification or clustering approach, data analysis method, and data set type and accuracy factor.

\section{Review of the selected behavior-based approaches}

Altaher [38] proposed an evolving hybrid neuro-fuzzy classifier (EHNFC) for Androidbased malware grouping utilizing consent based components. The proposed EHNFC not just has the capacity of distinguishing obscured malware utilizing fluffy tenets, yet can likewise advance its structure by adopting new malware recognition fluffy tenets to enhance its discovery exactness when utilized as a part of the location of more malware applications. To this end, a developing bunching technique for adjusting and advancing malware location fluffy tenets was changed to consolidate a versatile methodology for overhauling the radii and focuses of grouped authorization based components. This adjustment to the advancing bunching strategy improves group merging also, produces decides that are better custom-made to the input information, henceforth enhancing the characterization precision of the proposed EHNFC. The exploratory outcomes for the proposed EHNFC demonstrate that the proposition outflanks a few cutting-edge jumbled malware order approaches as far as a false negative rate (0.05) and false positive rate (0.05). The outcomes likewise show that the proposition identifies the Android malware superior to other neuro-fuzzy frameworks as far as precision (90\%).

Mohaisen et al. [39] proposed, a computerized and conduct based malware examination and marking framework called AMAL that addresses shortcomings of the current frameworks. AMAL comprises of two sub-frameworks, AutoMal and MaLabel. AutoMal gives instruments to gather low granularity behavioral curios that portray malware utilization of the document framework, memory, organize, what's more, registry, and does that by running malware tests in virtualized situations. On the other hand, MaLabel utilizes those ancient rarities to make delegate highlights, utilize them for building classifiers prepared by physically screened preparing tests, and utilize those classifiers to characterize malware tests into families comparable in conduct. AutoMal additionally empowers unsupervised learning, by executing various bunching calculations for tests gathering. An assessment of both AutoMal and MaLabel in view of medium-scale 
Table 3 A side-by-side comparison of the reviewed signature-based articles

\begin{tabular}{|c|c|c|c|c|}
\hline Method & Main idea & Advantages & Disadvantages & Target environment \\
\hline PMD & $\begin{array}{l}\text { Polymorphic Malware } \\
\text { Detection (PMD) [25] }\end{array}$ & $\begin{array}{l}\text { Low cost } \\
\text { High accuracy }\end{array}$ & $\begin{array}{l}\text { Increasing total feature } \\
\text { selection }\end{array}$ & Windows-based \\
\hline SigPID & $\begin{array}{l}\text { Significant permission } \\
\text { identification android } \\
\text { malware detection } \\
\text { (SigPID) [19] }\end{array}$ & $\begin{array}{l}\text { Low cost } \\
\text { High accuracy }\end{array}$ & Low scanning & Smartphone \\
\hline OpCode & $\begin{array}{l}\text { Graph malware detec- } \\
\text { tion [3] }\end{array}$ & $\begin{array}{l}\text { Low complexity } \\
\text { Low cost }\end{array}$ & $\begin{array}{l}\text { Low timely } \\
\text { High robustness }\end{array}$ & Embedded systems \\
\hline Droid & $\begin{array}{l}\text { Droid malware detection } \\
\text { [11] }\end{array}$ & Fast feature selection & High complexity & Smartphone \\
\hline APMD & $\begin{array}{l}\text { API malware detection } \\
\text { (APMD) [23] }\end{array}$ & $\begin{array}{l}\text { Low monitoring over- } \\
\text { head } \\
\text { High accuracy }\end{array}$ & High cost & Windows-based \\
\hline SVDD & $\begin{array}{l}\text { N-grams malware detec- } \\
\text { tion [20] }\end{array}$ & High detection accuracy & $\begin{array}{l}\text { Did not analyzing feature } \\
\text { selection }\end{array}$ & Windows-based \\
\hline SMD & $\begin{array}{l}\text { Smartphone malware } \\
\text { detection (SMD) [29] }\end{array}$ & $\begin{array}{l}\text { Combining static } \\
\text { malware analysis and } \\
\text { dynamic malware } \\
\text { analysis } \\
\text { Presenting novel the } \\
\text { clone and the muta- } \\
\text { tion mechanism }\end{array}$ & $\begin{array}{l}\text { Did not comparing with } \\
\text { other classification } \\
\text { approaches } \\
\text { Low accuracy }\end{array}$ & Smartphone \\
\hline SAAM & $\begin{array}{l}\text { Symbolic aggregate } \\
\text { approximation for mal- } \\
\text { wares (SAAM) [30] }\end{array}$ & $\begin{array}{l}\text { Best packet classification } \\
\text { High accuracy } \\
\text { Presenting a data trans- } \\
\text { formation method } \\
\text { to reduce the space } \\
\text { complexity }\end{array}$ & $\begin{array}{l}\text { Did not examine the } \\
\text { multiple packing } \\
\text { algorithms. }\end{array}$ & Windows-based \\
\hline SOMM & $\begin{array}{l}\text { Service-Oriented mobile } \\
\text { malware detection } \\
\text { (SoMM) [31] }\end{array}$ & $\begin{array}{l}\text { High detection accuracy } \\
\text { High scaling }\end{array}$ & $\begin{array}{l}\text { High traffic } \\
\text { Did not analyzing behav- } \\
\text { ior of malwares }\end{array}$ & Smartphone \\
\hline SPM & $\begin{array}{l}\text { Sequential pattern min- } \\
\text { ing (SMP) [32] }\end{array}$ & $\begin{array}{l}\text { High accuracy } \\
\text { Low overhead }\end{array}$ & $\begin{array}{l}\text { Did not analyzing feature } \\
\text { selection }\end{array}$ & Windows-based \\
\hline FPM & $\begin{array}{l}\text { Frequent pattern mining } \\
\quad \text { (FPM) [33] }\end{array}$ & $\begin{array}{l}\text { Presenting automatic } \\
\text { train approach }\end{array}$ & $\begin{array}{l}\text { Not analysis discrimina- } \\
\text { tive frequent behavior } \\
\text { patterns } \\
\text { High overhead }\end{array}$ & Windows-based \\
\hline MOED & $\begin{array}{l}\text { Multi-objective evo- } \\
\text { lutionary detection } \\
\text { (MOED) [34] }\end{array}$ & $\begin{array}{l}\text { High speed detection } \\
\text { High accuracy } \\
\text { Low overhead }\end{array}$ & $\begin{array}{l}\text { Using traditional detec- } \\
\text { tion engines }\end{array}$ & Smartphone \\
\hline Opcode & Opcode sequences [35] & $\begin{array}{l}\text { Prefect detection ratio of } \\
\text { unknown malware }\end{array}$ & $\begin{array}{l}\text { Did not analyze instance } \\
\text { selection }\end{array}$ & Smartphone \\
\hline MobA & Mobile android [24] & $\begin{array}{l}\text { Good attribute selection } \\
\text { Low overhead }\end{array}$ & $\begin{array}{l}\text { High complexity } \\
\text { Did not analysis counter- } \\
\text { measures }\end{array}$ & Smartphone \\
\hline SHMD & $\begin{array}{l}\text { Signature and Heuristic- } \\
\text { based malware detec- } \\
\text { tion [36] }\end{array}$ & $\begin{array}{l}\text { Low overhead } \\
\text { Best binary feature } \\
\text { selection }\end{array}$ & $\begin{array}{l}\text { High time complexity } \\
\text { High cost }\end{array}$ & Smartphone \\
\hline MKLDroid & $\begin{array}{l}\text { A multi-view context- } \\
\text { aware approach to } \\
\text { Android malware } \\
\text { detection [15] }\end{array}$ & $\begin{array}{l}\text { High efficiency } \\
\text { Run time detection }\end{array}$ & $\begin{array}{l}\text { High complexity } \\
\text { Did not analyzing feature } \\
\text { selection }\end{array}$ & Smartphone \\
\hline DBScan & $\begin{array}{l}\text { Hybrid pattern based } \\
\text { text mining approach } \\
\text { [17] }\end{array}$ & Low overhead & $\begin{array}{l}\text { High time } \\
\text { Low scalability }\end{array}$ & Windows-based \\
\hline DroidNative & $\begin{array}{l}\text { Android malware detec- } \\
\text { tor with control flow } \\
\text { patterns [37] }\end{array}$ & $\begin{array}{l}\text { Low time } \\
\text { High efficiency }\end{array}$ & $\begin{array}{l}\text { Low scalability } \\
\text { High cost }\end{array}$ & Smartphone \\
\hline BAM & $\begin{array}{l}\text { Hybrid malware detec- } \\
\text { tion with binary asso- } \\
\text { ciative memory [13] }\end{array}$ & High efficiency & High complexity & Windows-based \\
\hline
\end{tabular}


(4000 specimens) and expansive scale datasets (more than 115,000 samples) collected and broke down via AutoMal shows AMAL's adequacy in precisely describing, ordering, and gathering malware tests. MaLabel accomplishes an exactness of $99.5 \%$ and review of $99.6 \%$ to confident relations demand, and more than $98 \%$ of accuracy and evaluation for unsupervised classification.

Yuan et al. [40] presented a deep learning method to connect the components from the static investigation with elements from the dynamic investigation of Android applications. In addition, they actualized an Android malware detection engine based on the deep-learning method (DroidDetector) that can consequently distinguish whether a file has a malicious behavior or not. With a large number of Android applications, they tested DroidDetector and play out an in-depth examination of the elements that deep learning basically adventures to portray malware completely. The outcomes appear that deep learning is appropriate for characterizing Android malware and particularly compelling with the accessibility of additional preparation information. DroidDetector can accomplish 96.76\% detection accuracy, which traditional machine learning methods.

Boukhtouta et al. [41] presented the issue of fingerprinting perniciousness of activity with the end goal of recognition and arrangement. This research pointed first at fingerprinting perniciousness by utilizing two approaches: Deep Packet Inspection (DPI) and IP bundle headers arrangement. To this end, we consider malignant activity created from element malware examination as movement perniciousness ground truth. In light of this supposition, they exhibited how these two methodologies are utilized to recognize what's more, attribute maliciousness to the various threat. In this work, we concentrate the positive and negative angles for Deep Packet Review and IP bundle headers order. They assessed every approach in view of its recognition and attribution precision and additionally their level of multifaceted nature. The results of both methodologies have demonstrated promising outcomes as far as discovery; they are great possibility to constitute a collaboration to expand or prove recognition frameworks as far as runtime speed and grouping exactness.

Ding et al. [42] proposed an affiliation mining strategy based on API calls to recognize malware. To expand the identification speed of the Objective-Oriented association (OOA) mining, distinctive methodologies are exhibited: to enhance the govern quality, criteria for API determination are proposed to expel APIs that can't get to distinctly visit things; to discover affiliation decides that have solid segregation control, we characterize the manage utility to assess the affiliation runs; and to enhance the location exactness, a characterization strategy in view of numerous affiliation guidelines is embraced. The trials demonstrate that the proposed systems can essentially enhance the running velocity of OOA. In our investigations, the time cost for information mining is decreased by $32 \%$, and the time cost for arrangement is decreased by $50 \%$.

Eskandari et al. [43] presented a novel hybrid approach, HDM-Analyzer, is displayed which takes points of interest of dynamic and static investigation techniques for rising pace while protecting the precision at a sensible level. HDM-Analyzer can foresee the dominant part of basic leadership focuses on using the factual data which is assembled by element investigation; along these lines, they have no any performance overhead. The fundamental commitment of this paper is taking exactness preferred standpoint of the element investigation and consolidating it into static examination keeping in mind 
Table 4 A side-by-side comparison of the important factors in the signature-based detection of each article

\begin{tabular}{|c|c|c|c|c|c|}
\hline Case study & $\begin{array}{l}\text { Classification } \\
\text { approach }\end{array}$ & $\begin{array}{l}\text { Data analysis } \\
\text { method }\end{array}$ & Used dataset & Total dataset & $\begin{array}{l}\text { Accuracy } \\
\%\end{array}$ \\
\hline $\begin{array}{l}\text { Polymorphic } \\
\text { Malware Detection } \\
\text { [25] }\end{array}$ & K-means & Dynamic & ClamAV, VirusTotal, & 2876 & 99 \\
\hline $\begin{array}{c}\text { Android malware } \\
\text { detection [19] }\end{array}$ & SVM & Dynamic & Google play store & 5494 & 94 \\
\hline $\begin{array}{l}\text { Graph malware } \\
\text { detection [3] }\end{array}$ & Graph-SVM & Dynamic & Windows DLL calls & 6671 & 88 \\
\hline $\begin{array}{l}\text { Droid malware } \\
\text { detection [11] }\end{array}$ & SVM & Dynamic & Windows API library & 7000 & 98 \\
\hline $\begin{array}{l}\text { API malware detec- } \\
\text { tion [23] }\end{array}$ & $\begin{array}{l}\text { Naive Bayes and } \\
\text { Decision Tree- } \\
\text { SVM }\end{array}$ & Dynamic & Google play store & 7000 & 95 \\
\hline $\begin{array}{l}\text { N-grams malware } \\
\text { detection [20] }\end{array}$ & SVM & Dynamic & Google play store & 658 & 97 \\
\hline $\begin{array}{l}\text { Smartphone } \\
\text { malware detection } \\
\text { [29] }\end{array}$ & $\begin{array}{l}\text { K-means-artificial } \\
\text { immune system }\end{array}$ & Hybrid & $\begin{array}{r}\text { Android malware } \\
\text { database XVNA }\end{array}$ & 1300 & 89.8 \\
\hline $\begin{array}{l}\text { Symbolic aggregate } \\
\text { approximation for } \\
\text { malwares [30] }\end{array}$ & Naive Bayes and SVM & Dynamic & $\begin{array}{l}\text { Offensive comput- } \\
\text { ing and VX } \\
\text { heavens library }\end{array}$ & 8100 & 95.83 \\
\hline $\begin{array}{l}\text { Service-Oriented } \\
\text { mobile malware } \\
\text { detection [31] }\end{array}$ & $\begin{array}{c}\text { Naive Bayes and } \\
\text { Decision Tree }\end{array}$ & Hybrid & $\begin{array}{l}\text { Key Laboratory of } \\
\text { Network Security, } \\
\text { Fujian Normal } \\
\text { University }\end{array}$ & 3000 & 97.3 \\
\hline $\begin{array}{l}\text { Sequential pattern } \\
\text { mining [32] }\end{array}$ & $\begin{array}{l}\text { All-Nearest-Neigh- } \\
\text { bor, KNN, SVM J48 }\end{array}$ & Hybrid & VXHeaven website & 3200 & 95.2 \\
\hline $\begin{array}{l}\text { Frequent pattern } \\
\text { mining [33] }\end{array}$ & $\begin{array}{c}\text { Minimal contrast fre- } \\
\text { quent subgraphs }\end{array}$ & Static & Several websites & 2083 & 92 \\
\hline $\begin{array}{l}\text { Multi-objective evo- } \\
\text { lutionary detection } \\
\text { [34] }\end{array}$ & $\begin{array}{l}\text { Multi-objective evo- } \\
\text { lutionary by GA }\end{array}$ & Static & $\begin{array}{l}\text { Viruseshair and Virus- } \\
\text { Total websites }\end{array}$ & 9383 & 95.15 \\
\hline $\begin{array}{l}\text { Opcode sequences } \\
\text { [35] }\end{array}$ & $\begin{array}{l}\text { K-nearest neighbors } \\
\text { and SVM }\end{array}$ & Hybrid & VxHeavens website & 2000 & 92.9 \\
\hline Mobile android [24] & SVM & Hybrid & $\begin{array}{l}\text { Contagio Blogger } \\
\text { and VirusTotal Web } \\
\text { sites }\end{array}$ & 2500 & 98.7 \\
\hline $\begin{array}{l}\text { Signature and } \\
\text { Heuristic-based } \\
\text { Malware Detection } \\
\text { [36] }\end{array}$ & $\begin{array}{l}\text { SVM, J48, KNN, } \\
\text { Decision tree and } \\
\text { Random tree }\end{array}$ & Hybrid & MODROID website & 500 & 99.81 \\
\hline $\begin{array}{l}\text { A multi-view [15] } \\
\text { context-aware } \\
\text { approach to } \\
\text { Android malware } \\
\text { detection }\end{array}$ & $\begin{array}{l}\text { Multiple Kernel } \\
\text { Learning, SVM }\end{array}$ & Static & $\begin{array}{l}\text { Google Play, } \\
\text { AndroidDrawer, } \\
\text { FDroid }\end{array}$ & 6056 & 98.05 \\
\hline $\begin{array}{l}\text { Hybrid pattern } \\
\text { based text mining } \\
\text { approach [17] }\end{array}$ & $\begin{array}{l}\text { ANN, malicious } \\
\text { sequential pattern } \\
\text { based malware } \\
\text { detection }\end{array}$ & Hybrid & $\begin{array}{l}\text { Viruseshair and Virus- } \\
\text { Total websites }\end{array}$ & 8000 & 98.89 \\
\hline $\begin{array}{l}\text { Android malware } \\
\text { detector with } \\
\text { control flow pat- } \\
\text { terns [37] }\end{array}$ & Droid, CFGO-IL & Static & Several websites & 3158 & 93.57 \\
\hline $\begin{array}{l}\text { Hybrid malware } \\
\text { detection with } \\
\text { binary associative } \\
\text { memory [13] }\end{array}$ & $\begin{array}{l}\text { MLP, SVM, Naïve } \\
\text { Bayes, J48 }\end{array}$ & Hybrid & VX Heaven website & 52,183 & 98.6 \\
\hline
\end{tabular}


the end goal to enlarge the precision of static investigation. Truth be told, the execution overhead has been endured in learning stage; hence, it does not force on highlight extraction stage which is performed in examining operation. The exploratory outcomes illustrate that HDM-Analyzer accomplishes better general exactness and time manysided quality than static and element investigation strategies.

Miao et al. [44] presented a bilayer conduct reflection strategy in light of the semantic examination of dynamic API sequences. Operations on touchy framework assets and complex practices are disconnected in an interpretable way at various semantic layers. At the lower layer, crude API calls are joined to extract low-layer practices by means of information reliance investigation. At the higher layer, low-layer practices are further joined to build more intricate high-layer practices with great interpretability. The separated low-layer furthermore, high-layer practices are at last inserted into a high dimensional vector space. Henceforth, the disconnected practices can be specifically utilized by numerous prominent machine learning calculations. In addition, to handle the issue that considerate projects are not satisfactorily examined or malware and amiable projects are seriously imbalanced, an enhanced one-class bolster vector machine (OCSVM) named OC-SVM-Neg is proposed which makes utilization of the accessible negative examples. The trial comes about demonstrate that the proposed include extraction technique with OC-SVM-Neg beats double classifiers on the false caution rate and the speculation capacity.

Ming et al. [45] have presented a substitution attacks to cover comparable practices by harming behavior-based specifications. The key strategy for the attacks is to supplant a system call dependence graph to its semantically identical variations so that the comparable malware tests confidential unique family end up being characteristic. Accordingly, malware investigators need to put more endeavors into reconsidering the similar samples which may have been examined sometime recently. They distill general attacking strategies by mining more than 5200 malware tests' behavior specifications and execute a compiler-level model to automate replacement attacks. By evaluating on the real malicious examples, the effectiveness of the proposed method to obstruct several behaviorbased malware analysis tasks, such as clustering and malware comparison. Finally, they discussed likely countermeasures to support current malware protection.

Nikolopoulos and Polenakis [46] have proposed a graph-based model which using relations between gatherings of system-calls, distinguishes whether an unknown software sample is malicious or benign, and classifies a malevolent software to one of a set of an arrangement of known malware families. All the more correctly, clients used the System-call Dependency Graphs (or, for short, ScD-graphs), acquired by traces captured through dynamic taint investigation. The authors planed their model to be safe against strong changes applying our recognition and arrangement systems on a weighted coordinated graph, to be specific Group Relation Graph, or Gr-graph for short, coming about because of ScD-graph subsequent to gathering disjoint subsets of its vertices. For the discovery procedure, the authors proposed the Delta-comparability metric, and for the procedure of classification, they proposed the SaMe-similitude and NP-similarity measurements comprising the SaMe-NP closeness. At last, they evaluated their model for malware recognition and classification demonstrating its possibilities against malicious software measuring its identification rates and classification accuracy. 
Sheen et al. [47] have considered Android-based malware for examination and an adaptable recognition component is planned to utilize multi-feature collaborative decision fusion (MCDF). The distinctive features of a malicious record like the consent-based features and the API call based features are considered keeping in mind the end goal to give a superior discovery via preparing a gathering of classifiers and combining their choices utilizing collective approach in view of likelihood hypothesis. The execution of the proposed model is evaluated on a gathering of Android-based malware including diverse malware families and the outcomes demonstrate that the presented approach give a superior execution than best in class troupe plans accessible.

Norouzi et al. [48] have proposed distinctive classification techniques with a specific end goal to recognize malware in light of the element and conduct of each malware. A dynamic investigation technique has been exhibited for recognizing the malware features. A recommended program has been introduced for changing over a malware behavior executive history XML document to an appropriate WEKA instrument input. To represent the execution proficiency and preparing information and test, the authors apply the proposed ways to deal with a genuine contextual investigation information set utilizing WEKA instrument. The evaluation results described that the availability of the proposed data mining approach. In addition, their proposed data mining methodology is more proficient for identifying malware and behavioral classification of malware can be helpful to recognize malware in a behavioral antivirus.

Galal et al. [49] proposed a behavior-based features model that defines malicious action exhibited by malware example. To remove the proposed model, the authors first perform dynamic examination on a generally late malware dataset inside a controlled virtual environment and capture traces of API calls conjured by malware examples. The traces are then generalized into high-level features refer to as actions. The proposed method is evaluated using some famous classification methods such as random forests, decision tree and SVM. The experimental results show that the classifiers attain high precision and satisfactory results in the detection of malware variants.

\section{Summary of the reviewed behavior-based approaches}

According to the discussed and reviewed behavior-based detection approaches, the comparison of the proposed articles has illustrated in Table 5. Table 5 presents the main idea, advantages, disadvantages and target environment of each technical study in behavior-based approaches. The main advantage of behavior-based detection approaches is detecting all of the suspicious files according to their calls' behavior that increases the accuracy of malware prediction. The main disadvantage of the signature-based detection approaches is the runtime overhead. The target environment is categorized into three main platform including embedded systems, windows-based and smartphones. The most research studies in the behavior-based detection have used the smartphone environment for representing the proposed malware detection approach.

Also, Table 6 shows a technical comparison of the behavior-based detection factors in each article. These factors include case-study method, classification or clustering approach, data analysis method, used data set, total number of dataset and accuracy factor. 
Table 5 A comparison of the reviewed behavior-based articles

\begin{tabular}{|c|c|c|c|c|}
\hline Method & Main idea & Advantages & Disadvantages & Target environment \\
\hline DeepAM & $\begin{array}{l}\text { Deep learning malware } \\
\text { detection [9] }\end{array}$ & $\begin{array}{l}\text { Solving the encrypted } \\
\text { Problem in malware } \\
\text { detection } \\
\text { Higher accuracy }\end{array}$ & $\begin{array}{l}\text { High cost } \\
\text { High timely }\end{array}$ & Embedded systems \\
\hline QDFG & $\begin{array}{l}\text { Graph mining in mal- } \\
\text { ware detection [21] }\end{array}$ & $\begin{array}{l}\text { Reducing response } \\
\text { time }\end{array}$ & $\begin{array}{l}\text { High complexity } \\
\text { High cost }\end{array}$ & Smartphone \\
\hline DMDAM & $\begin{array}{l}\text { Android malware } \\
\text { detection [6] }\end{array}$ & $\begin{array}{l}\text { Reducing concepts for } \\
\text { increasing feature } \\
\text { selection } \\
\text { High accuracy }\end{array}$ & $\begin{array}{l}\text { High complexity } \\
\text { Run-time overhead }\end{array}$ & Smartphone \\
\hline AMP & $\begin{array}{l}\text { Android malware } \\
\text { detection [22] }\end{array}$ & High accuracy & High cost & Smartphone \\
\hline AMD & $\begin{array}{l}\text { Android malware } \\
\text { detection [38] }\end{array}$ & $\begin{array}{l}\text { Higher accuracy than } \\
\text { the other neuro-fuzzy } \\
\text { approaches } \\
\text { Minimum false positive } \\
\text { and false negative }\end{array}$ & $\begin{array}{l}\text { Did not considering } \\
\text { dynamic analysis of } \\
\text { Android apps } \\
\text { Run-time overhead }\end{array}$ & Smartphone \\
\hline AMAL & $\begin{array}{l}\text { AMAL: automated mal- } \\
\text { ware analysis [39] }\end{array}$ & $\begin{array}{l}\text { Providing high levels of } \\
\text { precision, recall, and } \\
\text { accuracy } \\
\text { Low cost }\end{array}$ & $\begin{array}{l}\text { IP reputation } \\
\text { High overhead }\end{array}$ & Smartphone \\
\hline AMCS & $\begin{array}{l}\text { Android Malware } \\
\text { Characterization and } \\
\text { Detection [40] }\end{array}$ & $\begin{array}{l}\text { Conducting static and } \\
\text { dynamic analyses to } \\
\text { extract features from } \\
\text { each applications } \\
\text { Deploying online test- } \\
\text { ing for Droid-detector }\end{array}$ & $\begin{array}{l}\text { High cost } \\
\text { High overhead on API } \\
\text { calls }\end{array}$ & Smartphone \\
\hline DPIM & $\begin{array}{l}\text { Deep Packet Inspection } \\
\text { for malware [41] }\end{array}$ & $\begin{array}{l}\text { High classification } \\
\text { accuracy } \\
\text { Independence from } \\
\text { packet payloads } \\
\text { Decoupling between } \\
\text { detection and attribu- } \\
\text { tion }\end{array}$ & $\begin{array}{l}\text { Datasets over fitting } \\
\text { High complexity }\end{array}$ & Windows-based \\
\hline OOM & $\begin{array}{l}\text { Objective Oriented } \\
\text { malware [42] }\end{array}$ & $\begin{array}{l}\text { Adapting multiple } \\
\text { association rules } \\
\text { Improve the running } \\
\text { speed of classification }\end{array}$ & $\begin{array}{l}\text { High complexity } \\
\text { High cost } \\
\text { Not analyzing } \\
\text { unmatched files }\end{array}$ & Windows-based \\
\hline HAM & $\begin{array}{l}\text { Hybrid analysis malware } \\
\text { [43] }\end{array}$ & $\begin{array}{l}\text { Low execution over- } \\
\text { head } \\
\text { High accuracy time }\end{array}$ & High time consumption & Windows-based \\
\hline BBA & $\begin{array}{l}\text { Bilayer behavior } \\
\text { abstraction [44] }\end{array}$ & Low overhead & $\begin{array}{l}\text { Did not analyzing } \\
\text { feature selection }\end{array}$ & Windows-based \\
\hline Mspec & $\begin{array}{l}\text { Malware specifications } \\
\text { [45] }\end{array}$ & $\begin{array}{l}\text { Good normalizing } \\
\text { features } \\
\text { Low execution time }\end{array}$ & $\begin{array}{l}\text { Did not analyzing the } \\
\text { accuracy conditions } \\
\text { High complexity }\end{array}$ & Windows-based \\
\hline SyCM & $\begin{array}{l}\text { System-call malware } \\
\text { [46] }\end{array}$ & $\begin{array}{l}\text { High accuracy } \\
\text { High dependency } \\
\text { analysis for calls }\end{array}$ & High time consumption & Smartphone \\
\hline ABM & $\begin{array}{l}\text { Android based malware } \\
\text { [47] }\end{array}$ & $\begin{array}{l}\text { Using multi-feature } \\
\text { attributes } \\
\text { High scalability }\end{array}$ & $\begin{array}{l}\text { High complexity } \\
\text { High execution time }\end{array}$ & Smartphone \\
\hline DBM & Behavioral malware [48] & $\begin{array}{l}\text { Extracting XML to } \\
\text { feature files } \\
\text { High scalability }\end{array}$ & High complexity & Windows-based \\
\hline MAPI & $\begin{array}{l}\text { Malicious code based } \\
\text { on API [49] }\end{array}$ & $\begin{array}{l}\text { Adding additional heu- } \\
\text { ristic occupations to } \\
\text { show more actions } \\
\text { High accuracy rates }\end{array}$ & $\begin{array}{l}\text { Not suitable for } \\
\text { samples of external } \\
\text { events } \\
\text { Existence analysis }\end{array}$ & Windows-based \\
\hline
\end{tabular}


Table 5 continued

\begin{tabular}{lllll}
\hline Method & Main idea & Advantages & Disadvantages & Target environment \\
\hline Cloudlntell & $\begin{array}{c}\text { Feature extraction } \\
\text { method in cloud [18] }\end{array}$ & $\begin{array}{l}\text { Lowest energy con- } \\
\text { sumption } \\
\text { High scalability }\end{array}$ & $\begin{array}{l}\text { High complexity } \\
\text { High response time }\end{array}$ & Windows-based \\
SDMS & $\begin{array}{c}\text { Security dependency } \\
\text { network for malware } \\
\text { detection [50] }\end{array}$ & $\begin{array}{ll}\text { Low response time } \\
\text { High accuracy }\end{array}$ & $\begin{array}{l}\text { High energy } \\
\text { High complexity }\end{array}$ & Windows-based \\
DFAMD & $\begin{array}{c}\text { Data flow android mal- } \\
\text { ware detection [51] }\end{array}$ & $\begin{array}{l}\text { High efficiency } \\
\text { Low overhead }\end{array}$ & $\begin{array}{l}\text { High complexity } \\
\text { High dependency }\end{array}$ & Smartphone \\
SCCMD & $\begin{array}{c}\text { So-called compression- } \\
\text { based malware detec- }\end{array}$ & High efficiency \\
tion [21] & High response time & Windows-based \\
DeepFlow & $\begin{array}{c}\text { Deep-learning malware } \\
\text { detection [52] }\end{array}$ & & Smartphone \\
\hline
\end{tabular}

\section{Discussion}

In this section, a statistical analysis of reviewed approaches of malware detection using data mining is presented. Figure 4 shows the statistical diagram for all of the classification methods in the selected malware detection approaches. In this report, the SVM method has most percentage for malware detection approach with $29 \%$, j48 has $17 \%$, NB has $10 \%$, RF has $5 \%$, ANN has $3 \%$ and the other methods have less than $2 \%$ usage in data mining results. We discover that the SMV method just has the best accuracy in the signature-based malware detection approaches using data mining.

Also, Fig. 5 shows the accuracy factor for each research. As shown, all of the accuracy factors higher than $80 \%$. The maximum accuracy percentage is $99.2 \%$ for the DPIM approach [41] and the minimum accuracy percentage is $86 \%$ for the DMDAM approach [22].

Also, Fig. 6 shows the main case study diagram of each research in malware detection. As shown, the recent researches have considered android smartphones to analyze malware detection approaches with $40 \%$. The symbolic code aggregation case studies in windows-based platform has $23 \%$, the pattern mining has $11 \%$, the system calls has $8 \%$ usage in malware detection.

In addition, Fig. 7 illustrates the total number of data set used for malware detection analysis in each research. In this figure, there are five research that use higher than 5000 real samples during the evaluation process. The BBA approach [44] has the maximum dataset with 17,000 samples and the AMD approach [38] has the minimum dataset with 500 samples.

Also, Fig. 8 shows the data analysis methods percentage in terms of static, dynamic and hybrid analysis in selected research. The most data analysis methods have used dynamic analysis with $51 \%$, the hybrid analysis has $29 \%$ and the static analysis has $20 \%$ usage. The $30 \%$ of the signature-based approaches have used the dynamic data analysis. The $65 \%$ of the behavior-based malware detection approaches have used the dynamic data analysis method. 
Table 6 A side-by-side comparison of the important factors in behavior-based detection of each article

\begin{tabular}{|c|c|c|c|c|c|}
\hline Case study & $\begin{array}{l}\text { Classification } \\
\text { approach }\end{array}$ & $\begin{array}{l}\text { Data analysis } \\
\text { method }\end{array}$ & Used dataset & Total dataset & $\begin{array}{l}\text { Accuracy } \\
\%\end{array}$ \\
\hline $\begin{array}{l}\text { Deep learning } \\
\text { malware detec- } \\
\text { tion [9] }\end{array}$ & DeepAM & Dynamic & $\begin{array}{l}\text { Windows API } \\
\text { calls in Comodo } \\
\text { Cloud Security } \\
\text { Center }\end{array}$ & 2000 & 98 \\
\hline $\begin{array}{l}\text { Graph mining in } \\
\text { malware detec- } \\
\text { tion }[21]\end{array}$ & Graph search & Dynamic & $\begin{array}{l}\text { Windows sandbox } \\
\text { malware }\end{array}$ & 6994 & 96 \\
\hline $\begin{array}{c}\text { Android malware } \\
\text { detection [6] }\end{array}$ & Random forest & Dynamic & $\begin{array}{l}\text { Android applica- } \\
\text { tions }\end{array}$ & 170 & 86 \\
\hline $\begin{array}{c}\text { Android malware } \\
\text { detection [22] }\end{array}$ & $\begin{array}{l}\text { Multilayer percep- } \\
\text { tron }\end{array}$ & Dynamic & Several websites & 734 & 97 \\
\hline $\begin{array}{c}\text { Android malware } \\
\text { detection [38] }\end{array}$ & $\begin{array}{l}\text { Evolving neuro- } \\
\text { fuzzy inference } \\
\text { system }\end{array}$ & Dynamic & $\begin{array}{l}\text { Google play and } \\
\text { android } \\
\text { Malware genome } \\
\text { Project }\end{array}$ & 500 & 90 \\
\hline $\begin{array}{l}\text { AMAL: automated } \\
\text { malware analysis } \\
\text { [39] }\end{array}$ & Decision trees & Dynamic & $\begin{array}{l}\text { Random sample } \\
\text { from internal } \\
\text { user and external } \\
\text { customers such } \\
\text { as antivirus com- } \\
\text { panies }\end{array}$ & 2086 & 98 \\
\hline $\begin{array}{l}\text { Android malware } \\
\text { characterization } \\
\text { and detection } \\
\text { [40] }\end{array}$ & $\begin{array}{l}\text { Deep belief net- } \\
\text { works }\end{array}$ & Hybrid & $\begin{array}{l}\text { Google play and } \\
\text { android } \\
\text { Malware genome } \\
\text { project }\end{array}$ & 1860 & 96.76 \\
\hline $\begin{array}{l}\text { Deep Packet } \\
\text { Inspection for } \\
\text { malware [41] }\end{array}$ & $\begin{array}{l}\text { BoostedJ48, J48, } \\
\text { Naïve Bayesian } \\
\text { and SVM }\end{array}$ & Dynamic & $\begin{array}{l}\text { Wireless and } \\
\text { Secure Networks } \\
\text { Research Lab }\end{array}$ & 4560 & 99 \\
\hline $\begin{array}{l}\text { Objective Oriented } \\
\text { malware [42] }\end{array}$ & $\begin{array}{l}\text { Multiple associa- } \\
\text { tion rules }\end{array}$ & Hybrid & Several websites & 8000 & 97.2 \\
\hline $\begin{array}{l}\text { Hybrid analysis } \\
\text { malware [43] }\end{array}$ & $\begin{array}{l}\text { Bayesian network, } \\
\text { Naive Bayes, Lazy } \\
\text { K-Stare }\end{array}$ & Hybrid & $\begin{array}{l}\text { Selected randomly } \\
\text { from malware } \\
\text { repository of } \\
\text { APA, the security } \\
\text { research labora- } \\
\text { tory at Shiraz } \\
\text { University }\end{array}$ & 3000 & 95.27 \\
\hline $\begin{array}{l}\text { Bilayer behavior } \\
\text { abstraction [44] }\end{array}$ & $\begin{array}{l}\text { SMV, Naïve Bayes, } \\
\text { decision tree, } \\
\text { logistic regression }\end{array}$ & Dynamic & $\begin{array}{l}\text { Open-access mal- } \\
\text { ware database } \\
\text { such as } \\
\text { VXHeaven website }\end{array}$ & 17,000 & 94 \\
\hline $\begin{array}{l}\text { Malware specifica- } \\
\text { tions [45] }\end{array}$ & $\begin{array}{l}\text { System call } \\
\text { dependency } \\
\text { graph }\end{array}$ & Dynamic & VXHeavens website & 5200 & 92 \\
\hline $\begin{array}{l}\text { System-call mal- } \\
\text { ware }[46]\end{array}$ & SaMe-NP & Dynamic & $\begin{array}{l}\text { Variety of com- } \\
\text { modity software } \\
\text { types including } \\
\text { editors, office } \\
\text { suites, media } \\
\text { players, }\end{array}$ & 2667 & 95.9 \\
\hline $\begin{array}{l}\text { Android based } \\
\text { malware [47] }\end{array}$ & $\begin{array}{r}\text { J48, SVM, IBk, } \\
\text { NaiveBayes }\end{array}$ & Static & $\begin{array}{l}\text { Google play and } \\
\text { android } \\
\text { Malware services }\end{array}$ & 2000 & 98.91 \\
\hline $\begin{array}{l}\text { Behavioral Malware } \\
\text { [48] }\end{array}$ & $\begin{array}{l}\text { Regression, SVM, } \\
\text { J48 }\end{array}$ & Dynamic & $\begin{array}{l}\text { Web data com- } \\
\text { mons library in } \\
\text { VirusSign and } \\
\text { VXHeaven }\end{array}$ & 7000 & 98.3 \\
\hline
\end{tabular}


Table 6 continued

\begin{tabular}{|c|c|c|c|c|c|}
\hline Case study & $\begin{array}{l}\text { Classification } \\
\text { approach }\end{array}$ & $\begin{array}{l}\text { Data analysis } \\
\text { method }\end{array}$ & Used dataset & Total dataset & $\begin{array}{l}\text { Accuracy } \\
\%\end{array}$ \\
\hline $\begin{array}{l}\text { Malicious code } \\
\text { based on API [49] }\end{array}$ & $\begin{array}{l}\text { Decision tree, SVM } \\
\text { and random } \\
\text { forest }\end{array}$ & Dynamic & $\begin{array}{l}\text { API hooking library } \\
\text { in VirusSign }\end{array}$ & 2000 & 96.89 \\
\hline $\begin{array}{l}\text { Feature extraction } \\
\text { method in cloud } \\
{[18]}\end{array}$ & $\begin{array}{l}\text { Decision tree, SVM, } \\
\text { Boosting }\end{array}$ & Static & $\begin{array}{l}\text { Random dataset of } \\
\text { VirusTotal }\end{array}$ & 15,000 & 99.69 \\
\hline $\begin{array}{l}\text { Security depend- } \\
\text { ency network for } \\
\text { malware detec- } \\
\text { tion [50] }\end{array}$ & $\begin{array}{l}\text { No read down and } \\
\text { no write up }\end{array}$ & Dynamic & VXHeavens website & 7257 & 93.92 \\
\hline $\begin{array}{l}\text { Data flow android } \\
\text { malware detec- } \\
\text { tion [51] }\end{array}$ & $K N N, L R, B N$ & Static & $\begin{array}{l}\text { VXHeavens website } \\
\text { and Google play }\end{array}$ & 2200 & 97.66 \\
\hline $\begin{array}{l}\text { So-called } \\
\text { compression- } \\
\text { based malware } \\
\text { detection [21] }\end{array}$ & $\begin{array}{l}\text { k-NN, QDA, LDA, } \\
\text { SVN, Decision } \\
\text { Trees, and ran- } \\
\text { dom forest }\end{array}$ & Dynamic & Cuckoo sandbox & 7507 & 99.3 \\
\hline $\begin{array}{l}\text { Deep-learning } \\
\text { malware detec- } \\
\text { tion [52] }\end{array}$ & $\begin{array}{l}\text { Naive Bayes, PART, } \\
\text { Logistic Regres- } \\
\text { sion, SVM and } \\
\text { MLP }\end{array}$ & Hybrid & $\begin{array}{l}\text { Google play, virus } \\
\text { share }\end{array}$ & 11,000 & 95.05 \\
\hline
\end{tabular}

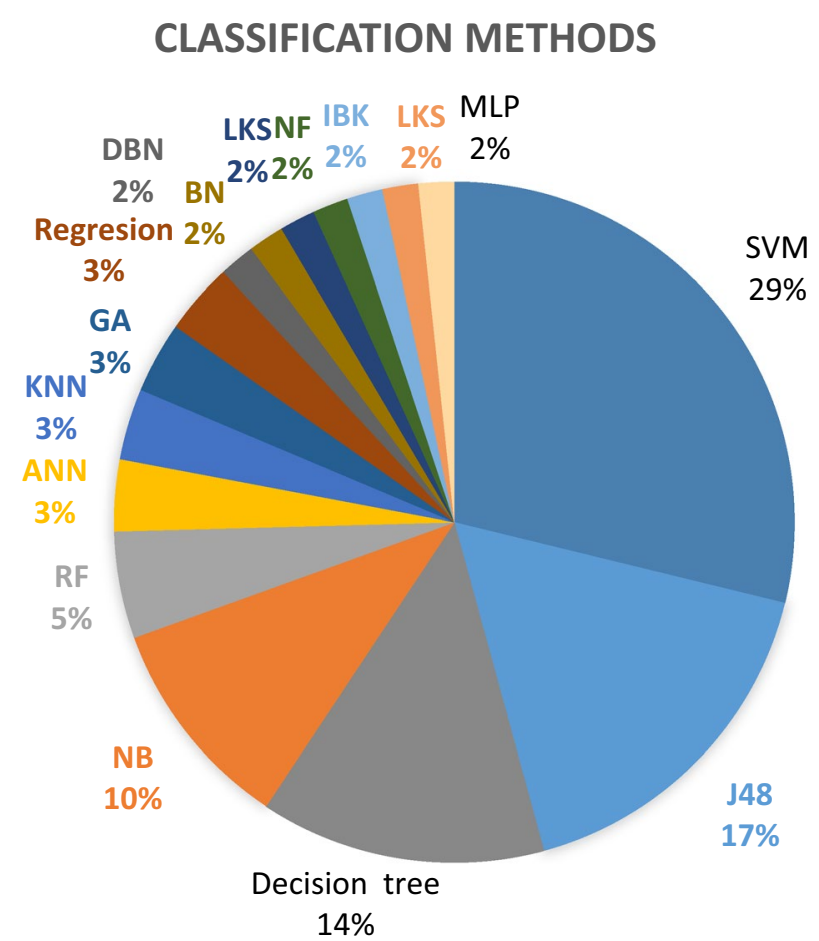

Fig. 4 Classification methods in malware detection mechanism

\section{Open issues}

Due to applying the survey on the malware detection approaches, the following research challenges as the open issues are presented that are not addressed by the research populations up to now. 


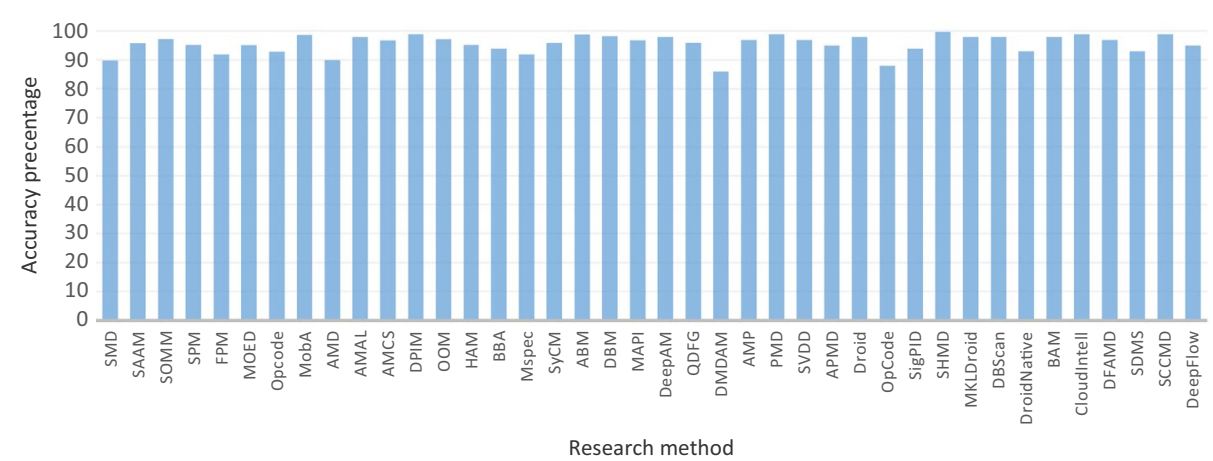

Fig. 5 Accuracy factor for selected approaches in malware detection
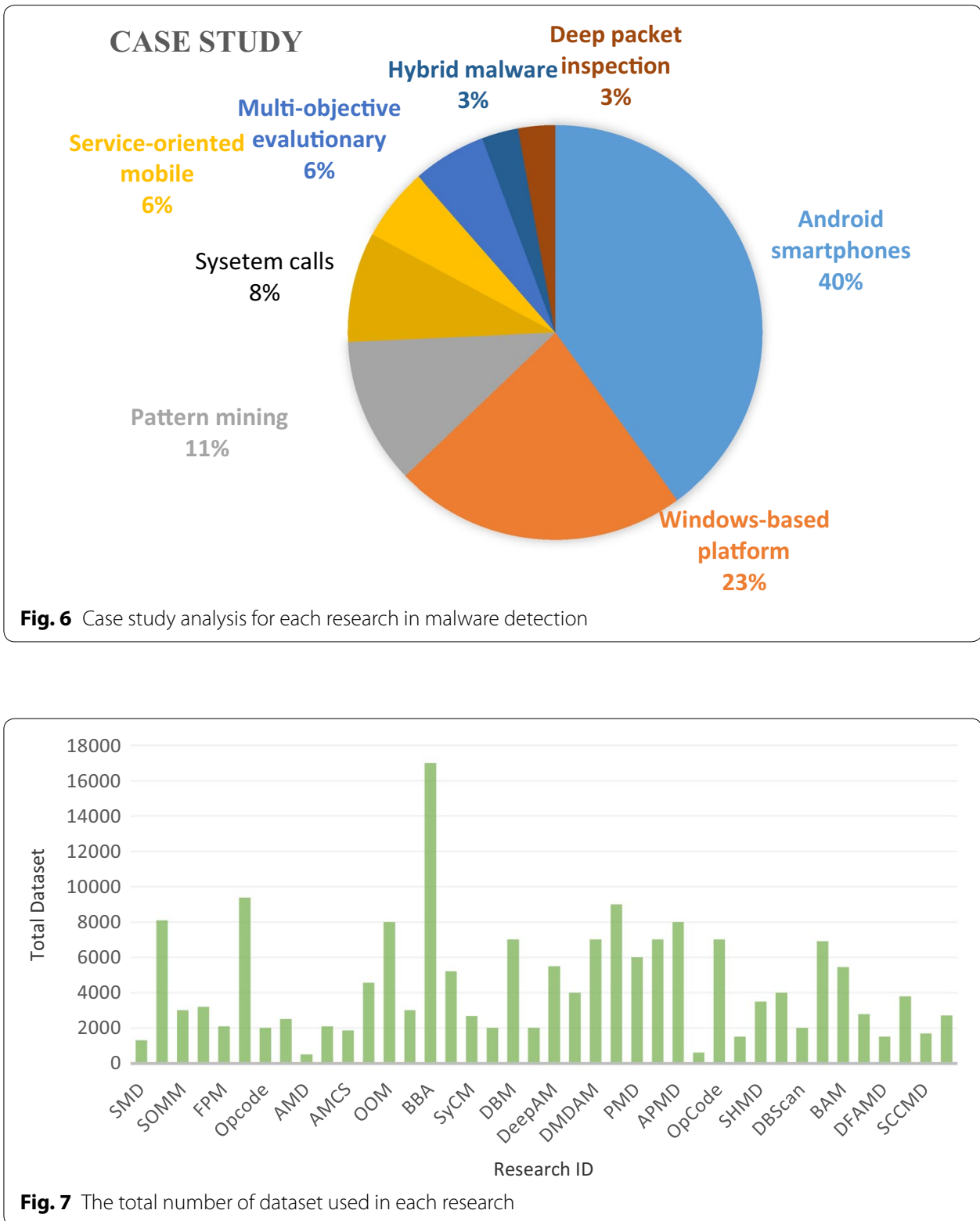


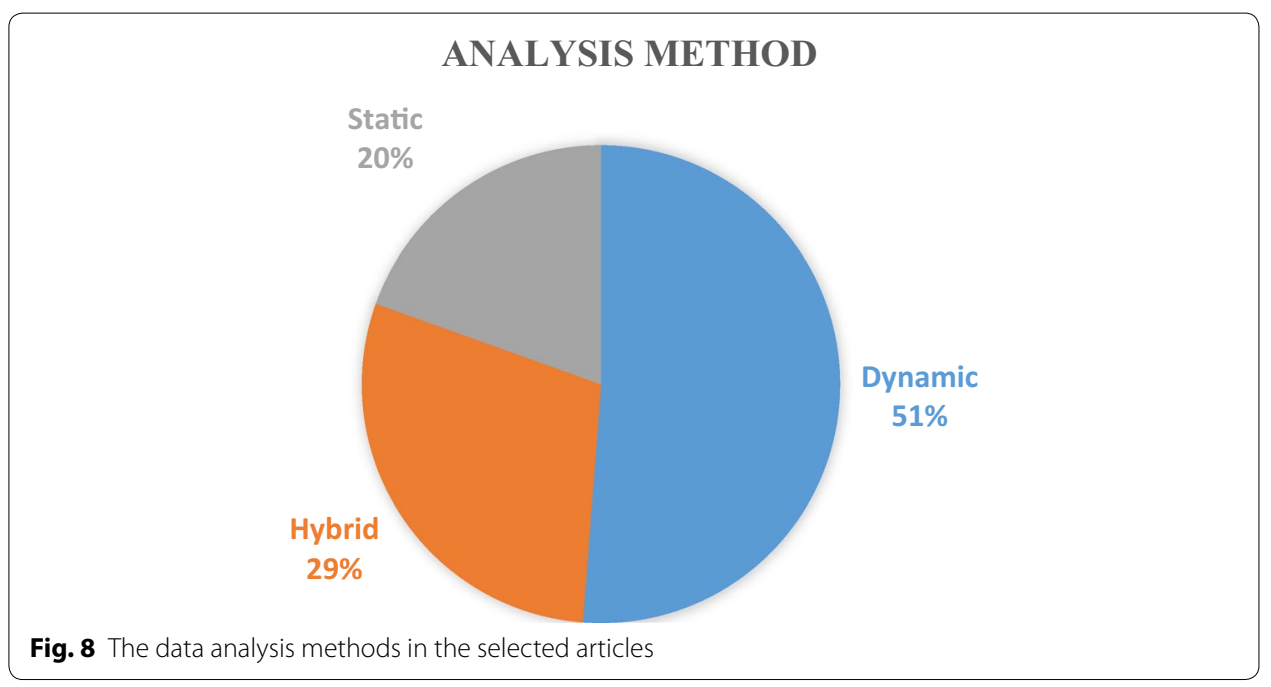

- Decryption/encryption detection: One of the important open issues in malware detection is information hiding malware techniques. Information hiding techniques are utilized to make information hard to take note. This practice ought not to be mistaken for encryption, in which the substance is disjointed, as it is rather clear. Such components are regularly utilized mutually to guarantee that a discussion stays indiscernible. Steganography is a standout amongst the most surely understood subfields of data stowing away and means to shroud mystery information in an appropriate transporter.

- Meta-heuristic detection: The malware detection analyses using meta-heuristic algorithms can influence the speed up of the execution time and the total accuracy factor of the data mining process.

- Real-time malware detection: Is based on hybrid analysis, secure multi-objective evolutionary malware detection, secure e-banking environments and secure healthcare systems are very challenging to recognize the malicious files and hidden attacks using data mining approaches.

Further studies are suggested to improve the accuracy of the related malware detection methods using evolutionary mechanisms.

In this survey, we performed a full description research to find more than 35 authors and different works. However, by considering the increasing development of studies on this topic, it is not possible to guarantee that all of the articles were recovered, particularly for 2010, because the research finished in July 2017.

\section{Suggestion criteria}

According to the existing discussion analysis, some technical suggestions are introduced to expand the malware detection approaches in the new platforms and architectures such as Internet of Things (IoT) applications, e-banking and social networks.

Some evolutionary methods can be improve the malware detection for predicting the polymorphism attacks in the electronic wallet applications. For example, a meta-heuristic algorithm finds the optimal signature detection for a polymorphism malware attacks in the electronic mobile payments. 
Context-aware detection is a new idea for dynamic malware detection approaches in the IoT applications based on semantic signature that categorize API calls with respect to the most interactions between end user and application layer of the IoT. When the smart devices cannot interact between user devices and datacenters, the reliability and availability of the smart services have been decreased.

Providing a safe condition for the huge data collection such as big data against the malware attacks is the key challenge for the malware detection for navigating big data security. Therefore, to select the minimal sample space of the malware damage, the data collection and storing big data can be navigate using data mining and synthesis methods.

\section{Conclusion}

This paper presented a systematic literature survey of the malware detection approaches using data mining. The reviewed and papers were investigated and classified into two main categories; (1) signature-based and (2) behavior-based approaches. The malware detection approaches were compared and analyzed according to various essential factors such as classification approaches, data analysis methods, the number of the used dataset, accuracy factor and case study analysis. The advantage and disadvantage of each method were deliberated in the malware detection methods. Most of the selected articles in data mining are behavior-based techniques. In the malware analysis stage, the most case studies are proposed for the android smartphones. In addition, using metaheuristic algorithms in malware detection analysis can speed up and improve the execution time and the overall accuracy of the data mining process. As the experimental results, we observed that the SVM method has most percentage for malware detection approach with 29\%, j48 has 17\%, Decision tree has 14\%, NB has $10 \%$, BF has $5 \%$ and the other methods have less than $3 \%$ usage in data mining results. We discover that the SVM method just has the best accuracy in the signature-based malware detection approaches using data mining. In addition, the maximum accuracy percentage is $99.2 \%$ for the DPIM approach and the minimum accuracy percentage is $86 \%$ for the DMDAM approach. Also, we observed that the recent researches have considered android smartphones to analyze malware detection approaches with $40 \%$. The symbolic code aggregation case studies in windows-based platform has $23 \%$, the pattern mining has $11 \%$, the system calls has $8 \%$ usage in malware detection. Finally, we have seen that The $30 \%$ of the signature-based approaches have used the dynamic data analysis. The $65 \%$ of the behavior-based malware detection approaches have used the dynamic data analysis method. As an important open issue, some important topics such as secure multi-objective malware, e-banking environments, and healthcare systems malware attacks are challenging areas to recognize the malicious files and hidden attacks.

Authors' contributions

AS as the corresponding author. $\mathrm{RH}$ as the co-author. Both authors read and approved the final manuscript.

Author details

1 Department of Computer Engineering, Science and Research Branch, Islamic Azad University, Tehran, Iran. ${ }^{2}$ Department of Computer Engineering, Shahr-e-Qods Branch, Islamic Azad University, Tehran, Iran.

Acknowledgements

Not applicable.

Competing interests

The authors declare that they have no competing interests. 
Availability of data and materials

Not applicable.

\section{Consent for publication}

Not applicable.

\section{Ethics approval and consent to participate}

We confirm that this manuscript has not been published elsewhere and is not under consideration by another journal. All authors have approved the manuscript and agree with its submission.

\section{Funding}

Not applicable.

\section{Publisher's Note}

Springer Nature remains neutral with regard to jurisdictional claims in published maps and institutional affiliations.

Received: 20 July 2017 Accepted: 2 January 2018

Published online: 12 January 2018

\section{References}

1. Souri A, Norouzi M, Asghari P (2017) An analytical automated refinement approach for structural modeling largescale codes using reverse engineering. Int J Inf Technol 9:329-333. https://doi.org/10.1007/s41870-017-0050-7

2. Souri A, Navimipour NJ, Rahmani AM (2017) Formal verification approaches and standards in the cloud computing: a comprehensive and systematic review. Comput Stand Interfaces. https://doi.org/10.1016/j.csi.2017.11.007

3. Hashemi H, Azmoodeh A, Hamzeh A, Hashemi S (2017) Graph embedding as a new approach for unknown malware detection. J Comput Virol Hacking Tech 13:153-166. https://doi.org/10.1007/s11416-016-0278-y

4. Park JH (2017) Novel approaches for applying linguistic processing techniques based on pattern recognition and machine learning. JIPS (J Inf Process Syst) 13:643-652

5. Souri A, Asghari P, Rezaei R (2017) Software as a service based CRM providers in the cloud computing: challenges and technical issues. J Serv Sci Res 9:219-237. https://doi.org/10.1007/s12927-017-0011-5

6. Bhattacharya A, Goswami RT (2017) DMDAM: data mining based detection of android malware. In: Mandal JK, Satapathy SC, Sanyal MK, Bhateja V (eds) Proceedings of the first international conference on intelligent computing and communication springer Singapore, Singapore, pp 187-194

7. Nikolopoulos SD, Polenakis I (2017) A graph-based model for malware detection and classification using system-call groups. J Comput Virol Hacking Tech 13:29-46. https://doi.org/10.1007/s11416-016-0267-1

8. Pektaş A, Acarman T (2017) Classification of malware families based on runtime behaviors. J Inf Secur App 37:91-100. https://doi.org/10.1016/j.jisa.2017.10.005

9. Ye Y, Chen L, Hou S, Hardy W, Li X (2017) DeepAM: a heterogeneous deep learning framework for intelligent malware detection. Knowl Inf Syst. https://doi.org/10.1007/s10115-017-1058-9

10. Safarkhanlou A, Souri A, Norouzi M, Sardroud SEH (2015) Formalizing and verification of an antivirus protection service using model checking. Procedia Comput Sci 57:1324-1331. https://doi.org/10.1016/j.procs.2015.07.443

11. Li Z, Sun L, Yan Q, Srisa-an W, Chen Z (2017) DroidClassifier: efficient adaptive mining of application-layer header for classifying android malware. In: Deng R, Weng J, Ren K, Yegneswaran V (eds) Security and privacy in communication networks: 12th international conference, securecomm 2016, Guangzhou, China, October 10-12, 2016, Proceedings. Springer International Publishing, Cham, pp 597-616

12. Malhotra R, Jangra R (2017) Prediction \& assessment of change prone classes using statistical \& machine learning techniques. J Inf Process Syst 13(4):778-804. https://doi.org/10.3745/JIPS.04.0013

13. Chowdhury M, Rahman A, Islam R (2018) Malware analysis and detection using data mining and machine learning classification. In: Abawajy J, Choo K-KR, Islam R (eds) International conference on applications and techniques in cyber security and intelligence: applications and techniques in cyber security and intelligence. Springer International Publishing, Cham, pp 266-274

14. Palumbo P, Sayfullina L, Komashinskiy D, Eirola E, Karhunen J (2017) A pragmatic android malware detection procedure. Comput Secur 70:689-701. https://doi.org/10.1016/j.cose.2017.07.013

15. Narayanan A, Chandramohan M, Chen L, Liu Y (2017) A multi-view context-aware approach to Android malware detection and malicious code localization. Empir Softw Eng. https://doi.org/10.1007/s10664-017-9539-8

16. Mohamed GAN, Ithnin NB (2018) SBRT: API signature behaviour based representation technique for improving metamorphic malware detection. In: Saeed F, Gazem N, Patnaik S, Saed Balaid AS, Mohammed F (eds) Recent trends in information and communication technology. Proceedings of the 2nd international conference of reliable information and communication technology (IRICT 2017). Springer International Publishing, Cham, pp 767-777

17. Malhotra A, Bajaj K (2016) A hybrid pattern based text mining approach for malware detection using DBScan. CSI Trans ICT 4:141-149. https://doi.org/10.1007/s40012-016-0095-y

18. Siddiqui M, Wang MC, Lee J (2008) A survey of data mining techniques for malware detection using file features. In: Proceedings of the 46th annual southeast regional conference on xx. 2008. ACM

19. Sun L, Li Z, Yan Q, Srisa-an W, Pan Y (2016) SigPID: significant permission identification for android malware detection. In: 201611 th international conference on malicious and unwanted software (MALWARE), pp 1-8

20. Boujnouni ME, Jedra M, Zahid N (2015) New malware detection framework based on N-grams and support vector domain description. In: 201511 th international conference on information assurance and security (IAS), pp 123-128 
21. Wuechner T, Cislak A, Ochoa M, Pretschner A (2017) Leveraging compression-based graph mining for behaviorbased malware detection. IEEE Trans Dependable Secur Comput. https://doi.org/10.1109/tdsc.2017.2675881

22. Bhattacharya A, Goswami RT (2017) Comparative analysis of different feature ranking techniques in data miningbased android malware detection. In: Satapathy SC, Bhateja V, Udgata SK, Pattnaik PK (eds) Proceedings of the 5th international conference on frontiers in intelligent computing: theory and applications: FICTA 2016, Volume 1. Springer Singapore, Singapore, pp 39-49

23. Fan Cl, Hsiao HW, Chou CH, Tseng YF (2015) Malware detection systems based on API log data mining. In: 2015 IEEE 39th annual computer software and applications conference, pp 255-260

24. Wang P, Wang Y-S (2015) Malware behavioural detection and vaccine development by using a support vector model classifier. J Comput Syst Sci 81:1012-1026. https://doi.org/10.1016/j.jcss.2014.12.014

25. Fraley JB, Figueroa M (2016) Polymorphic malware detection using topological feature extraction with data mining. In: SoutheastCon 2016, pp 1-7

26. Sun M, Li X, Lui JC, Ma RT, Liang Z (2017) Monet: a user-oriented behavior-based malware variants detection system for android. IEEE Trans Inf Forensics Secur 12:1103-1112

27. Sun H, Wang X, Buyya R, Su J (2017) CloudEyes: cloud-based malware detection with reversible sketch for resourceconstrained internet of things (loT) devices. Softw Pract Exp 47:421-441. https://doi.org/10.1002/spe.2420

28. Tang Y, Xiao B, Lu X (2011) Signature tree generation for polymorphic worms. IEEE Trans Comput 60:565-579. https://doi.org/10.1109/TC.2010.130

29. Wu B, LuT, Zheng K, Zhang D, Lin X (2014) Smartphone malware detection model based on artificial immune system. China Commun 11:86-92. https://doi.org/10.1109/CC.2014.7022530

30. Bat-Erdene M, Park H, Li H, Lee H, Choi MS (2017) Entropy analysis to classify unknown packing algorithms for malware detection. Int J Inf Secur 16(3):227-248. https://doi.org/10.1007/s10207-016-0330-4

31. Cui B, Jin H, Carullo G, Liu Z (2015) Service-oriented mobile malware detection system based on mining strategies. Pervasive Mob Comput 24:101-116. https://doi.org/10.1016/.pmcj.2015.06.006

32. Fan Y, Ye Y, Chen L (2016) Malicious sequential pattern mining for automatic malware detection. Expert Syst Appl 52:16-25. https://doi.org/10.1016/j.eswa.2016.01.002

33. Hellal A, Romdhane LB (2016) Minimal contrast frequent pattern mining for malware detection. Comput Secur 62:19-32. https://doi.org/10.1016/j.cose.2016.06.004

34. Martín A, Menéndez HD, Camacho D (2016) MOCDroid: multi-objective evolutionary classifier for Android malware detection. Soft Comput 21:7405-7415. https://doi.org/10.1007/s00500-016-2283-y

35. Santos I, Brezo F, Ugarte-Pedrero X, Bringas PG (2013) Opcode sequences as representation of executables for datamining-based unknown malware detection. Inf Sci 231:64-82. https://doi.org/10.1016/j.ins.2011.08.020

36. Rehman Z-U, Khan SN, Muhammad K, Lee JW, Lv Z, Baik SW, Shah PA, Awan K, Mehmood I (2017) Machine learningassisted signature and heuristic-based detection of malwares in Android devices. Comput Electr Eng. https://doi. org/10.1016/j.compeleceng.2017.11.028

37. Alam S, Qu Z, Riley R, Chen Y, Rastogi V (2017) DroidNative: automating and optimizing detection of Android native code malware variants. Comput Secur 65:230-246. https://doi.org/10.1016/j.cose.2016.11.011

38. Altaher A (2016) An improved Android malware detection scheme based on an evolving hybrid neuro-fuzzy classifier (EHNFC) and permission-based features. Neural Comput Appl 28:4147-4157. https://doi.org/10.1007/ s00521-016-2708-7

39. Mohaisen A, Alrawi O, Mohaisen M (2015) AMAL: high-fidelity, behavior-based automated malware analysis and classification. Comput Secur 52:251-266. https://doi.org/10.1016/i.cose.2015.04.001

40. Yuan Z, Lu Y, Xue Y (2016) Droiddetector: android malware characterization and detection using deep learning. Tsinghua Sci Technol 21:114-123. https://doi.org/10.1109/TST.2016.7399288

41. Boukhtouta A, Mokhov SA, Lakhdari N-E, Debbabi M, Paquet J (2016) Network malware classification comparison using DPI and flow packet headers. J Comput Virol Hacking Tech 12:69-100. https://doi.org/10.1007/ s11416-015-0247-X

42. Ding $Y$, Yuan $X$, Tang $K$, Xiao $X$, Zhang $Y$ (2013) A fast malware detection algorithm based on objective-oriented association mining. Comput Secur 39(Part B):315-324. https://doi.org/10.1016/j.cose.2013.08.008

43. Eskandari M, Khorshidpour Z, Hashemi S (2013) HDM-Analyser: a hybrid analysis approach based on data mining techniques for malware detection. J Comput Virol Hacking Tech 9:77-93. https://doi.org/10.1007/ s11416-013-0181-8

44. Miao Q, Liu J, Cao Y, Song J (2016) Malware detection using bilayer behavior abstraction and improved one-class support vector machines. Int J Inf Secur 15:361-379. https://doi.org/10.1007/s10207-015-0297-6

45. Ming J, Xin Z, Lan P, Wu D, Liu P, Mao B (2016) Impeding behavior-based malware analysis via replacement attacks to malware specifications. J Comput Virol Hacking Tech 13:193-207. https://doi.org/10.1007/s11416-016-0281-3

46. Nikolopoulos SD, Polenakis I (2016) A graph-based model for malware detection and classification using system-call groups. J Comput Virol Hacking Tech 13:29-46. https://doi.org/10.1007/s11416-016-0267-1

47. Sheen S, Anitha R, Natarajan V (2015) Android based malware detection using a multifeature collaborative decision fusion approach. Neurocomputing 151(Part 2):905-912. https://doi.org/10.1016/j.neucom.2014.10.004

48. Norouzi M, Souri A, Samad Zamini M (2016) A data mining classification approach for behavioral malware detection J Comput Netw Commun 2016:9. https://doi.org/10.1155/2016/8069672

49. Galal HS, Mahdy YB, Atiea MA (2016) Behavior-based features model for malware detection. J Comput Virol Hacking Tech 12:59-67. https://doi.org/10.1007/s11416-015-0244-0

50. Mao W, Cai Z, Towsley D, Feng Q, Guan X (2017) Security importance assessment for system objects and malware detection. Comput Secur 68:47-68. https://doi.org/10.1016/j.cose.2017.02.009

51. Wu S, Wang P, Li X, Zhang Y (2016) Effective detection of android malware based on the usage of data flow APIs and machine learning. Inf Softw Technol 75:17-25. https://doi.org/10.1016/j.infsof.2016.03.004

52. Dali Z, Hao J, Ying Y, Wu D, Weiyi C (2017) DeepFlow: deep learning-based malware detection by mining Android application for abnormal usage of sensitive data. In: 2017 IEEE symposium on computers and communications (ISCC), pp 438-443 